\title{
Prevalence of anterior cross bite in preadolescent orthodontic patients attending an orthodontic clinic
}

\author{
S N Vithanaarachchi ${ }^{1}$, L S Nawarathna ${ }^{2}$
}

\begin{abstract}
Introduction Anterior cross bite is a common malocclusion and early treatment is indicated. Determining its prevalence is important to plan orthodontic services.
\end{abstract}

Objective To assess the prevalence and associated features of anterior cross bite in pre-adolescent patients attending an orthodontic clinic.

Methods A hospital based cross sectional study was conducted. Seven hundred and twenty one consecutive patients were examined for anterior cross bite. Anterior cross bite were recorded when maxillary incisor/s occluded lingually to mandibular incisor/s in centric occlusion. Mandibular displacement, gingival recession, tooth mobility, presence of posterior cross bite and skeletal pattern were also assessed.

Results Of the 721 patients, 193 (26.7\%) had anterior cross bite. Twenty two (11.4\%) had both anterior and posterior cross bite. Among patients with anterior cross bite $62 \%$ had unilateral involvement and $38 \%$ had bilateral involvement. One hundred $(51.8 \%)$ had involvement of only one incisor while $64(33.2 \%)$ had involvement of two incisors. Class 1 skeletal pattern was found in $103(53.37 \%)$ patients with anterior cross bite, Class 2 skeletal pattern in 33 $(17.1 \%)$ and Class 3 skeletal pattern in $57(29.53 \%)$. Mandibular displacement was present in 93 (48.19\%) patients and $5(2.5 \%)$ showed tooth wear in anterior cross bite. Gingival recession was seen in $43(22.3 \%)$ and tooth mobility of involved lower incisors in 12 $(6.2 \%)$.

Conclusion The prevalence of anterior cross bite is high in pre-adolescent patients attending an orthodontic clinic.

Ceylon Medical Journal 2017; 62:189-192

DOI: http://doi.org/10.4038/cmj.v62i3.8523

\section{Introduction}

Anterior cross bite is a common malocclusion and it is usually evident in early mixed dentition. Salzman defined anterior cross bite as the lingual placement of maxillary incisors in relation to the opposing mandibular teeth when both arches are in centric occlusion [1]. Studies report prevalence of $7-10 \%$ in children in mixed dentition [2]. A national survey in Iraq reported prevalence of $5.5 \%$ [3]. Prevalence of anterior cross bite of $24 \%-36 \%$ have been reported in orthodontic patients $[4,5]$.

Depending on the etiology and clinical presentation, anterior cross bite can be classified into three main types namely dento-alveolar, skeletal and functional [6,7]. Dento-alveolar anterior cross bite often involves a single tooth rather than multiple teeth. This simple anterior cross bite is mainly of dental origin and these patients have normal anteroposterior skeletal relationship. Skeletal anterior cross bite usually occurs as a result of a skeletal discrepancy in the maxilla (retrognathic) or the mandible (prognathic). Functional anterior cross bite is a type of pseudo class III malocclusion in which the mandible is postured forward from its true centric position [8].

Several factors are reported as causes of anterior cross bite, including a lingual eruption path of maxillary incisors, retained primary incisors, potential crowding, presence of supernumerary teeth, trauma and class III skeletal pattern.

Anterior cross bite clinically manifests with reverse over jet, premature contact of cross bite teeth leading to displacement of the mandible, gingival recession as well as mobility of the lower incisors involved in the cross bite [9].

${ }^{1}$ Department of Community Dental Health, Faculty of Dental Sciences, University of Peradeniya and ${ }^{2}$ Department of Statistics and Computer Sciences, Faculty of Science, University of Peradeniya, Sri Lanka. Correspondence: SNV, E-mail: <nvithanaarachchi3@gmail.com>. Received 4 May 2017 and revised version accepted 24 July 2017. 
Treatment of anterior cross bite is recommended in primary and early mixed dentition, whether it is of skeletal or dentoalveolar origin [10]. Early correction of anterior cross bite eliminates mandibular displacement thus promoting establishment of centric relationship [11]. If neglected this may cause abrasion of the labial surfaces of upper incisors which may damage the periodontal support of lower incisors involved in the cross bite [12]. Furthermore this may exert strain on the orofacial structures, with adverse effects on the temporomandibular joint and masticatory system [13]. Therefore early intervention and correction of anterior cross bite would eliminate complications and promote establishment of centric relationship.

Accurate information on prevalence and factors associated with anterior cross bite is necessary to plan orthodontic services Therefore it is important to clinically evaluate patients who present with cross bite. The current study aims to assess the prevalence and associated features of anterior cross bite in preadolescent orthodontic patients.

\section{Methods}

We carried out a cross sectional, hospital based, observational study of 721 patients attending the Division of Orthodontics, University Dental Hospital, Peradeniya.

All consenting participants were clinically examined using dental mirror, probe and overjet ruler by the principal investigator and anterior cross bite was recorded when maxillary incisor/s (central and /lateral incisors) occluded lingually to mandibular incisor/s in centric occlusion. Mandibular displacement, gingival recession, tooth mobility, presence of posterior cross bite and skeletal pattern were assessed. Standard palpation method was used to clinically assess the skeletal pattern.

Patients who had previous orthodontic treatment, cleft lip /palate or other craniofacial syndromes and patients with supernumerary teeth were excluded from the study. These exclusion criteria have been adopted by other studies $[14,15]$.

Test-re test reliability was assessed by randomly selecting 30 participants and reassessing them 30 days after the initial assessment.

The study was approved by the Ethical Review Committee of Faculty of Dental Sciences, University of Peradeniya. The parents provided informed consent for their children to participate in the study.
Chi squared test and Fisher's exact test were used to check the association between variables. Statistical analysis was carried out using the statistical software $R$.

\section{Results}

The sample consisted of 721 patients. The age ranged from 8 years to 15 years with a mean age of 11.47 years. One hundred and ninety three $(26.7 \%)$ had anterior cross bite. Among those with anterior cross bite 98 (50.3\%) were females and 95 $(49.7 \%)$ were males. The mean age was 10.87 years (range 8-15 years). Twenty two (11.4\%) patients with anterior cross bite had posterior cross bite.

Among patients with anterior cross bite $62 \%$ had unilateral involvement and $38 \%$ had bilateral involvement. Right side was involved in $84 \%$ and left side was involved in $50 \%$.

One hundred (51.8\%) had involvement of only one incisor tooth, $64(33.2 \%)$ had involvement of two incisors, $6(3.1 \%)$ had involvement of three incisors and 23(11.92\%) had involvement of all four incisors. Upper right central incisor (11) was involved in $24.6 \%$, upper right lateral incisor (12) was involved in $28.83 \%$, upper left central incisor (21) was involved in $19.82 \%$ and upper left lateral incisor (22) was involved in $25.83 \%$.

One hundred and three (53.37\%) patients with anterior cross bite had class 1 skeletal pattern, $33(17.1 \%)$ had class 2 and $57(29.53 \%)$ had class 3 skeletal pattern. Class 1 and class 3 skeletal patterns were significantly associated with anterior cross bite $(p<0.05)$. Patients who had anterior cross bite with mandibular displacement $(53.76 \%)$ also showed significant association with class I skeletal pattern. Of the patients who had both anterior cross bite and posterior cross bite $45.45 \%$ had class III skeletal pattern.

Among 193 patients with anterior cross bite 93(48.19\%) had mandibular displacement. Only five $(2.5 \%)$ patients with anterior cross bite showed tooth wear. Gingival recession was present in $43(22.3 \%)$ and tooth mobility of involved lower incisors was present in $12(6.2 \%)$.

\section{Discussion}

This study found that of 721 patients attending the Division of Orthodontics, University Dental Hospital, 26.7\% had anterior cross bite. The results of the anterior cross bite in this study were similar to the results of other studies conducted in the Asian region [4,5]. Among the anterior cross bite patients, $22(11.4 \%)$ had posterior cross bite and its association was clinically significant. Dacosta et al. 
also reported that $14.3 \%$ had coexisting of posterior cross bite [16]. The percentage of males and females among patients with anterior cross bite were similar. This finding was similar to that reported among school children in Brazil [17].

When the side of involvement of anterior cross bite was considered, $62 \%$ had unilateral involvement and $38 \%$ affected bilaterally. In this sample $84 \%$ had right side occurrence and $50 \%$ had left side involvement. This finding was similar to the results obtained by some other studies which highlighted the relatively higher frequency of unilateral cross bite than that of bilateral cross bite [16].

With regard to affected incisors the majority of patients of anterior cross bite involved a single tooth $(51.8 \%)$, two involved teeth were found in $33.16 \%$, three involved teeth were found in $3.11 \%$ and $11.92 \%$ involved all four incisors. This showed that single tooth involvement was most frequent finding among the patients with anterior cross bite. These results were comparable with previous studies done by Abdulla in 1996 (18) and Al. Huwaizi in 2000 [9].

Lateral incisors were more commonly affected by anterior cross bite $(28.83 \%$ on the right side and $25.83 \%$ on the left) than central incisors ( $24.62 \%$ on the right side and $19.82 \%$ on left side) as shown on figure 02 . This result was also confirmed by a national Iraqi survey on anterior cross bite and may be due to its palatal development position $[3,19]$.

When the skeletal pattern associated with anterior cross bite was considered, class 1 relationship showed the highest percentage and both class 1 and class 3 skeletal patterns showed statistically significant association with anterior cross bite in this study. This result was consistent with that of a study by Dacosta in Nigeria that showed that anterior cross bite was more frequent among class 1 malocclusion than others [16]. This research finding of the current study further highlights that it is needed to intervene anterior cross bite in early stage to support to express the normal growth potential of maxilla. However, when both anterior and posterior cross bites were associated together, which was more significantly related with the class III skeletal pattern (45.45\%) and which highlights the need of treatment with functional orthopedics to address the skeletal discrepancy.

In the present study $48.19 \%$ had mandibular displacement with anterior cross bite and it was statistically significant. The concept that continuous mandibular displacement either forward or laterally may create future temporomandibular disorders is still questionable with various research findings. However, it is important to eliminate Ceylon Medical Journal mandibular displacement due to anterior cross bite in growing children with orthodontic treatment to establish centric occlusion and to avoid occlusal trauma [11].

Tooth wear, gingival recession and mobility of teeth involved in cross bite are considered the main indicators of occlusal trauma. The present study demonstrates a statistically significant association between these clinical parameters and anterior cross bite. It is paramount to take early measures to correct anterior cross bite to prevent such complications.

\section{Acknowledgement}

We would like to thank all patients who participated in the study. Further we extend our gratitude to G.W.D.A. Gunatanthne for his assistance in data analysis.

\section{Conflict of interest}

There are no conflicts of interest.

\section{References}

1. Salzman JA. Handicapping malocclusion assessment to establish treatment priority. Am J Orthod 1968; 54: 749-69.

2. Jones JW. O'Neill PD. Anterior cross bite and mobile lower central incisors in a 7-year-old patient: A case report. Dent Update 1996; 29: $434-41$.

3. Alhuwaiz AF, Al-Alousi WK, Al-Mulla AA. A National Iraqi Survey on Anterior Cross Bite. Iraqi Orthod J 2005: 1: 1-3.

4. Naeem S, Asad S, Waheed-Ul Hamid M. Prevalence of cross bite in orthodontic patients. Pakistan Oral \& Dental Journal 2009: 29: 27980.

5. Sultana N, Hassan GS, Jha D, et al. Prevalence of cross bite among the orthodontic patients in Bangabandhu Sheikh Mujib Medical University. Bangladesh J Medicine 2015; 26: 9-12.

6. Phulari BS. Interceptive orthodontics: Orthodontics Principals and Practice. $1^{\text {st }}$ Ed. Jaypee Brothers Medical Publishers, New Delhi 2011.

7. Millet D. Welbury R. Clinical Problem Solving in Orthodontics and Paediatric Dentistry, Elsevier Churchill Livingstone, Edinburgh. 2005. 
8. Singh G. Text book of Orthodontics, $1^{\text {st }} E d$, Jaypee Brothers Medical Publishers, New Delhi 2004.

9. Houston WJB, Walthers Orthodontic Notes. $4^{\text {th }}$ $E d$, Bristol Wright PSG, 1983.

10. Jirgensone I Liepa A. Abeltins A. Anterior cross bite correction in primary and mixed dentition with removal inclined bite plane, Stomatologija. 2008; 10: $140-4$.

11. Kurol J, Berlurd L. Longitudinal study and costbenefit analysis of the effect of early treatment of posterior cross-bites in the primary dentition. Eur J Orthod 1986; 8: 127-30.

12. Richardson A. Early Interceptive treatment, interceptive orthodontics, $4^{\text {th }}$ ed, Bristol Dental Association. 1999.

13. Petern S. Bondermark L. Soderfeldt B. A systematic review concerning early orthodontic treatment of unilateral posterior cross bite. Angle Orthod 2003: 73: 588 -96.
14. Allen D, Rebellato J, Sheats R, Ceron AM. Skeletal and dental contributions to posterior crossbites. Angle Orthod 2003; 73: 515-24.

15. Nimkarny, Miles PG, O' Relly MT, Weyant RJ, The validity of maxillary expansion indices. Angle Orthod 1995; 65: 321 -26.

16. Dacosta OO, Utomi IL. A clinical review of cross bite in an orthodontic population. West Afr $J$ Med 2011; 30: 24-8.

17. Cuc A, Cuc O. Reverse Crossbite-statistical study in the period of mixed dentition. J Orthod 2004; 31: 107-14

18. Abdulla NM. Occlusal features and perception a sample of 13-17 years old adolescents. Theses, University of Baghdad 1996.

$\mathrm{Al}$ - Huwaizi AF. Oclusal features in a sample of Yemeni students age $10-15$ years. Theses, University of Baghdad, 2000.

19. Thilander B, Bjerklin K. Posterior cross bite and temporomandibular disorders (TMDs): need for orthodontic treatment? Eur J Orthod 2012; 34: $667-73$.

This is an open-access article distributed under the terms of the Creative Commons Attribution License, which permits unrestricted use, distribution, and reproduction in any medium, provided the original author and source are credited. 